\title{
Indígenas na Cidade do Rio de Janeiro
}

Marcos Alexandre dos Santos Albuquerque*

\begin{abstract}
Resumo
Esse artigo aborda a condição atual da população indígena na região metropolitana da cidade do Rio de Janeiro. A partir de uma análise da situação dos indígenas nas cidades brasileiras, argumento que a organização indígena nesse contexto se direciona para a contestação do "limbo jurídico" ao qual estão submetidos. Centro meu argumento no exemplo da Aldeia Maracanã, que por conta de sua mobilização produziu ampla visibilidade social indígena, constrangendo assim o governo para a construção de políticas públicas para essa população.
\end{abstract}

Palavras-chave: Aldeia Maracanã; índios urbanos; Rio de Janeiro; poder público.

\begin{abstract}
This article analyzes the current condition of the indigenous population in the metropolitan area of the city of Rio de Janeiro. From an analysis of the situation of indigenous people in the Brazilian cities, I argue that indigenous organization in this context challenge the "legal limbo" to which they are subjected. I center my argument in the example of Maracanã Village, that due to a large mobilization has produced social visibility for indigenous, constraining the government to formulate public policies for this population.
\end{abstract}

keywords: Maracanã Village, Urban Indians, Rio de Janeiro; government.

\section{Introdução ${ }^{1}$}

Neste artigo convido o leitor a analisar uma questão contemporânea que teve bastante repercussão recentemente, refiro-me à presença indígena nas cidades brasileiras e particularmente ao fenômeno da Aldeia Maracanã no Rio de Janeiro.

Para começar a entender o que fazem os indígenas nas cidades proponho uma arqueologia da "questão indígena” nacional de forma a mapear suas interseções na atualidade. A partir de uma antropologia histórica (Oliveira, 1999a; 1999b) defendo que a categoria índio/indígena é produto do aparelho administrativo do estado, é uma definição político-administrativa. Portanto, teoricamente, penso a categoria índio/indígena como um instrumento políticoadministrativo do poder tutelar tal como o tema foi definido por Souza Lima (1995).

Essa distinção teórica instrumentaliza a análise da construção de uma grave questão social que pesa na consciência política do Brasil. Trata-se da chamada "questão indígena",

\footnotetext{
* Doutor em Antropologia Social pela Universidade Federal de Santa Catarina (PPGAS/UFSC), professor adjunto na Universidade do Estado do Rio de Janeiro (UERJ).marcosdada@yahoo.com.br

1 Agraço ao Professor Dr. José Ribamar Bessa Freire e aos colegas do Pró-Índio (UERJ), a Toni Lotar e Cordelia Fourneau e aos indígenas da Aldeia Maracanã.
} 
ou seja, do lugar sociopolítico desse coletivo na formação do país. O percurso histórico dos modelos de gestão desse que era pensado como um "problema" foi, primeiro, o da "guerra como política" e, com o advento da república, o da "política como guerra". A passagem de um modelo para outro, e o funcionamento do segundo, foi analisada por Souza Lima (1995) sob a noção de poder tutelar.

O poder tutelar foi instrumentalizado pelo governo através da criação em 1910 do SPILTN (Serviço de Proteção aos Índios e Localização do Trabalhadores Nacionais), depois, em 1918, apenas SPI. O órgão esteve atrelado a diversos Ministérios: da Agricultura, Indústria e Comércio (MAIC, 1910/30); do Trabalho, Indústria e Comércio (MTIC, 1930/34); da Guerra (1934/39); e da Agricultura (1939/67). O poder tutelar pode ser basicamente descrito como a passagem da "guerra como política à política como guerra", pois, ao se fazer a "paz", se reatualiza a guerra sob diferentes modos (Souza Lima, 1995). No exercício do poder tutelar, a violência aberta do período imperial se transforma em violência simbólica no período republicano (ibid.).

O poder tutelar se constitui num dispositivo disciplinar do estado brasileiro cujo exercício implica obter o monopólio dos atos de definir, controlar e administrar a população indígena e seus bens (terra, recursos minerais, saúde, educação e outros). Portanto, o poder tutelar promoveu o deslocamento do "direito à identidade' para uma forma externa de atribuição" (Souza Lima, 1995:119), esses parâmetros foram compostos sobre um suposto "grau" de integração do indígena à sociedade nacional ("assimilados", "arredios", "destribalizados" e outros). Dessa forma os indígenas foram definidos, classificados e administrados com o intuito de promover a extinção gradual das afinidades étnicas, permitindo assim a "assimilação" dessas populações ao grosso da população "brasileira" (ibid.).

É somente desse ponto de vista histórico e político que se pode de fato compreender a criação dos "territórios indígenas". Os "territórios indígenas" são parte do quadro administrativo do Estado no processo de regularização fundiária do país. Ao isolar os povos nativos em aldeias procurava-se apaziguar os conflitos fundiários entre nativos e colonizador. Desse modo, o poder tutelar pretendia vencer, pela "não violência", a resistência dos povos nativos em se fixarem em lugares definidos pelo Estado ao mesmo tempo em que constituía sobre eles poder administrativo pleno (ibid.).

O efeito dos "aldeamentos" era imobilizar a população nativa no campo a fim de criar uma mão de obra livre e, ao mesmo tempo, muito barata, mantendo assim as cidades livres do inchaço populacional e dos problemas que isso trazia. Como parte do trabalho político do Estado é dissimular, sendo o discurso ambíguo uma das formas por excelência dessa atividade (ibid.), os "territórios indígenas" menos do que proteger a população nativa a tornavam "cativa" de um território restrito e escasso de recursos.

Com a imposição da imobilidade aos povos nativos, o Estado pode administrar a "passagem" dessa população de "índios" a trabalhadores rurais. Na medida em que as más condições das aldeias os fizeram migrar e se inserirem na massa da população pobre do campo, criou-se a invisibilidade dessa população e a suposta diminuição de seu contingente.

Nesse processo, geraram-se as definições administrativas de "desaldeados”, "aculturados", "isolados", "em contato intermitente", "em contato permanente" e outros como o resultado positivo ${ }^{2}$ do poder tutelar. Assim, tanto a noção de "desaldeado" como a de "aculturado" serviram, e servem ainda hoje, como dispositivos para retirar ao indígena a sua presença e continuidade espacial e temporal, ou seja, para negar a permanência do indígena no campo da história.

2 Positivo no sentido foucaultiano, como descrição e conhecimento acumulativo que produz e investe na disseminação de categorias do saberdisciplina. 


\section{Os indígenas nas grandes cidades brasileiras}

Nos resultados do Censo brasileiro de 1991 constatou-se o total de 294 mil indígenas, sendo 223 mil em regiões rurais (76,1\% do total) e 71 mil em áreas urbanas (23,9\%). No Censo de 2000, os novos dados mostraram que a população indígena havia dobrado, agora eram 734 mil pessoas e, mais curioso ainda, a maior parte delas, 383.298, viviam em cidades, e 350 mil em áreas rurais. No Censo de 2010 a população indígena estava em 817.963 mil pessoas, um aumento anual de 1,1\%. Porém na área urbana houve um decréscimo, 315.180 mil pessoas, uma redução de 68 mil (sendo a maior redução na Região Sudeste). Segundo se especulou, "essas pessoas que deixaram de se classificar como indígenas na área urbana podem não ter nenhuma afinidade com seu povo de origem e a inclusão dos quesitos referentes ao pertencimento étnico e à língua falada no domicílio pode ter sido um fator de influência quanto à declaração de ser ou não indígena” (Santos; Teixeira, 2011, apud IBGE, 2012:12)”.

A Tabela 1 mostra os dados da população indígena entre os anos 1991 e 2010:

Tabela 1

População indígena no Brasil (1991-2010)

\begin{tabular}{|c|c|c|c|}
\hline \multirow{2}{*}{ Total 1} & 1981 & 2000 & 2010 \\
\hline & 146.815 .790 & 169.872 .856 & 190.755 .799 \\
\hline Não indígena & 145.986 .780 & 167.932 .053 & 189.931.228 \\
\hline \multirow[b]{2}{*}{ Urbana (1) } & 294.131 & 734.127 & 817.963 \\
\hline & 110.996 .829 & 137.925 .238 & 160.925 .792 \\
\hline Não indígena & 110.494 .732 & 136.620 .255 & 160.605 .299 \\
\hline \multirow[t]{2}{*}{ Indígena } & 71.026 & 383.298 & 315.180 \\
\hline & 35.818 .961 & 31.947 .618 & 29.830.007 \\
\hline Não indígena & 35.492 .049 & 31.311 .798 & 29.325 .929 \\
\hline Indígena & 223.105 & 350.829 & 502.783 \\
\hline
\end{tabular}

O que os últimos censos revelam é uma nova realidade da distribuição da população indígena no país. Dos 20 municípios com maior número de habitantes indígenas, 10 são capitais. Isso mostra que a realidade do indígena que está no meio urbano é significativamente o contexto das grandes cidades.

Esse quadro tem muitas explicações, uma das mais evidentes pode ser encontrada num documento do próprio IBGE, o Censo Agropecuário relativo a 2006. Nele se demonstra que a concentração da propriedade da terra no Brasil continua aumentando e, em consequência direta, diminui-se o número de estabelecimentos com menos de 10 hectares, que são os pobres do campo, cerca de 2,5 milhões de pessoas, que ocupam 2,7\% do território nacional. $\mathrm{O}$ outro lado desses números mostra que "são os fazendeiros do agronegócio, que representam menos de $1 \%$ dos estabelecimentos, mas controlam $46 \%$ de todas as terras" (editorial, Brasil de Fato, 08/10/2009).

O Brasil passou a ser assim o país com a maior concentração da propriedade rural do mundo. Existem no país 16 milhões de pessoas que sobrevivem na condição de semterra e 23 milhões de trabalhadores rurais que sobrevivem em estado de pobreza. Na Região Nordeste o território ocupado por pequenas propriedades (menores de 10 hectares) diminuiu drasticamente. Em relação a 1980 foram menos 707 mil hectares, e em relação a 1996 foi de 325 mil hectares (-8\%) (ibid.). O "Mapa de conflitos envolvendo injustiça ambiental e 
Saúde no Brasil”, elaborado pela FIOCRUZ e FASE e lançado em maio de $2010,{ }^{3}$ mostra que as populações mais injustiçadas são em primeiro lugar os indígenas $(33,67 \%)$ seguidos por agricultores familiares $(31,99 \%)$ e os quilombolas $(21,55 \%)$.

Assim a população indígena segue o mesmo caminho que os pobres no campo e se encaminha para as cidades. Como bem colocou Baines (2004, $s / p)$ :

\begin{abstract}
A própria política indigenista tem contribuído à migração para as cidades. A ideologia do SPI visava a uma pressuposta integração rápida dos índios à sociedade nacional, o que favorecia o estabelecimento de áreas reduzidas para os índios e a liberação das demais terras para ocupação pelos brancos. A falta de terras adequadas para sua sobrevivência é um dos fatores que leva à migração indígena e à busca de trabalho assalariado em fazendas e cidades.
\end{abstract}

Por outro lado, outro quadro parece se somar a este acima citado, trata-se de relacionar o aumento do latifúndio e da concentração de terra no Brasil como o aumento da presença indígena nos grandes centros urbanos e, com isso, a construção de uma rede cada vez mais ampla de apoio, do poder público e da sociedade, e de formação e domínio dos códigos formais de representação e poder político, o que vem constituindo um aumento do associativismo indígena e, com isso, de sua mobilização étnica e visibilidade social. A invisibilidade do indígena nas cidades começa a mudar com o aparecimento de organizações indígenas a partir de 1988 com a promulgação da Constituição que, como escreveu o próprio Baines (ibid.):

\begin{abstract}
ao reconhecer o direito dos índios de se representarem juridicamente, resultou na criação de dezenas de organizações indígenas e numa mobilização política indígena sem precedentes. Como consequência da sua própria mobilização política, um número crescente de líderes indígenas está migrando para as cidades para participar do movimento indígena, e muitos jovens indígenas estão migrando para estudarem e se prepararem para enfrentar a sociedade nacional.
\end{abstract}

É nesse sentido que para o IBGE o crescimento exponencial da população indígena no Brasil é fruto da autoidentificação como indígenas de pessoas que estão nas cidades, e não propriamente o aumento da população indígena no campo. Marta Azevedo (do Instituto Socioambiental/ISA), em entrevista concedida a Carvalho (2007, $s / p$ ), afirmou que no Brasil atualmente existe:

um ambiente mais favorável para que as pessoas se autodeclarem indígenas: houve um movimento de valorização étnica, de valorização de temas do meio ambiente, além de políticas públicas que priorizam e valorizam segmentos específicos da população; existem políticas compensatórias e afirmativas. Contam também a existência do movimento indígena organizado, e uma tendência da política internacional.

Todo esse processo de abertura democrática e de construção de direitos minimizou preconceitos e a invisibilidade social dos indígenas. Apesar do número de indígenas nas cidades ser muito grande, e mesmo levando em conta o fato de que a migração para as cidades vem acontecendo pelo menos desde os anos 1950, período de urbanização intensa do país, a FUNAI atua basicamente nas Terras Indígenas. Embora o censo do IBGE seja utilizado como fonte fidedigna, não existe de fato outros dados que possam corroborá-lo. Para Baines (2004, $s / p)$, “a identidade indígena nos centros urbanos configura-se nitidamente como uma identidade social contextual”. Nesse sentido:

A mesma pessoa pode se considerar indígena em alguns contextos, e não em outros, ou apelar a outras identidades genéricas geradas historicamente em situações de contato interétnico, como caboclo, índio civilizado, descendente de índio, remanescente, índio misturado etc.

$3 \mathrm{http} / / /$ www.conflitoambiental.icict.fiocruz.br

152 - Cadernos do Desenvolvimento Fluminense, Rio de Janeiro, N.7, pp. 149 - 168, jan./jun. 2015 
A fim de conseguirem reconhecimento e efetivação de seus direitos diferenciados como indígenas nas cidades, a saída tem sido a organização autônoma desses povos em associações, como forma de criar um instrumento legal que os represente junto ao poder público.

Embora o governo já viesse atuando de maneira esparsa em alguns contextos, a questão dos indígenas nas cidades apareceu oficialmente em 2006, durante a $1^{\text {a }}$ Conferência Nacional dos Povos Indígenas. Os delegados indígenas aprovaram a inclusão de um capítulo sobre "índios urbanos" no documento final do encontro. Os vinte e quatro itens tratam de demandas por território, por educação e saúde. Durante o Fórum Urbano Mundial, em 2010, o presidente da FUNAI na época, Márcio Meira, disse que “a maior parte da população indígena ainda vive - e espero que continue vivendo sempre - nos seus territórios tradicionais. Mas as cidades brasileiras estão cada vez mais recebendo povos indígenas" (Abdala, 2010, s/p).

É interessante notar o fato de que a FUNAI espera que os povos indígenas jamais deixem suas terras, essa lógica está presente no modelo de gestão do órgão, motivo pelo qual ele jamais se preparou para dar conta de tais demandas. A concepção do órgão é a de que "o papel da FUNAI não deve ser o de implementar ela mesma os programas, mas desenvolver as linhas das políticas que deverão ser implementadas pelo governo federal no bojo da ação direta dos ministérios" (Carvalho, 2007, $s / p$ ).

No meio desse "limbo jurídico", alguns estados e municípios, na sua maior parte através de secretarias de direitos humanos, têm construído políticas públicas para a população indígena. É o caso de São Paulo, cujo governo estadual implantou o Decreto 48.532, de 9 de março de 2004, que criou o Conselho Estadual dos Povos Indígenas de São Paulo (CEPISP). Em Porto Alegre foi criado dentro da Secretaria de Direitos Humanos, o Núcleo de Políticas Públicas para Povos Indígenas, em Campo Grande, em 2005, passou a funcionar o Conselho Municipal de Direitos e Defesa dos Povos Indígenas, e existem muitos outros casos semelhantes. No geral o que tais articulações entre os três níveis do poder público, federal, estadual e municipal, têm realizado é uma divisão do trabalho de atendimento aos indígenas distribuindo atribuições específicas aos seus distintos ministérios e secretarias, promovendo assim certa ambiguidade e, consequentemente, um desconhecimento desses povos de como proceder em relação a tão distintas instâncias.

Assim, acaba-se não construindo uma direção clara no plano federal para as políticas de atendimento aos povos indígenas, cuja ambiguidade permite a rarefação da atuação do poder público e o cruzamento de procedimentos burocráticos que acabam efetivamente não promovendo as tais políticas que lhe são cabíveis. Há mais de 15 anos tramita no Congresso Nacional o projeto de lei do novo "Estatuto dos Povos Indígenas", ensaia-se a possibilidade de que sejam estabelecidas no novo texto normas específicas que determinem explicitamente a garantia dos direitos dos povos indígenas que estejam em situação urbana.

As principais demandas dos povos indígenas nas cidades são por moradia, educação e saúde. Um dos pontos principais de mobilização dos povos indígenas nas cidades é a questão do atendimento à saúde, onde essas populações enfrentam outro "limbo jurídico", já que não são claras as orientações e obrigações dos órgãos públicos responsáveis por esse setor. De forma autônoma, muitos povos indígenas vêm se organizando em parceria com órgãos públicos a fim de construir políticas públicas de atendimento à saúde.

Segundo a assessoria de comunicação da FUNASA, "a orientação geral é assistir apenas indígenas de aldeias reconhecidas pela FUNAI (...) aqueles que deixam suas aldeias 
e passam a viver em cidades devem ser atendidos pela rede de saúde pública, como todos os outros cidadãos" (Carvalho, 2007, $s / p$ ). Por este ponto de vista, caberia à FUNASA apenas "fazer uma interlocução com o gestor local, o município, para dar assistência melhor a esses índios”. A FUNASA fica, portanto, responsável apenas por fornecer alguns benefícios não disponibilizados pelo serviço de saúde.

Para a coordenação da FUNASA em Brasília,

\footnotetext{
Uma grande dificuldade para o atendimento aos indígenas nas cidades é o problema de como reconhecer quem é ou não indígena. O modelo mais conhecido para remediar esse conflito vem sendo aplicado em São Paulo, pelos Pankararu do Real Parque. Tal modelo preza pelo conhecimento de suas redes de parentesco, os contatos deles com outros povos são usados pela FUNASA para conseguir identificar esta população que vive espalhada pela cidade. Além dos próprios Pankararu, a associação que os representa em São Paulo, a SOS-CIP, também cadastrou os demais indígenas oriundos do Nordeste. (Carvalho, 2007, s/p)4
}

Agentes indígenas de saúde (AIS) trabalham nas cidades de Manaus, Campo Grande, São Paulo e Porto Alegre.

O artesanato aparece como uma fonte de renda cada vez maior para muitos indígenas nas grandes cidades. Além de ser uma fonte de renda, o artesanato está se constituindo num importante "lugar" onde muitos indígenas passaram a apostar como forma de criar visibilidade social e, assim, ampliar o alcance do apelo por direitos. O grande exemplo nesse sentido é a cidade de São Paulo, cujos espaços de venda de artesanato e performances indígenas são os espaços de maior visibilidade dessa população na cidade. Em algumas cidades foram associações de artesãos que começaram a mobilizar sua comunidade na busca de reconhecimento e direitos. Em Manaus existe desde 1984 a Associação das Mulheres do Alto Rio Negro (Amarn), que, com o artesanato, "conseguiu tirar do isolamento mulheres que foram trazidas para Manaus como empregadas domésticas, sem conhecidos na cidade, sem direito a folgas e, por vezes, sem direito a salários” (Carvalho, 2007, $s / p$ ). Em Campo Grande, há 17 anos no centro da cidade, os Terena mantêm quiosques onde vendem frutas, legumes e cerâmicas. Muitos indígenas Guarani estão nos centros de grandes cidades vendendo artesanato, na maioria das vezes sem qualquer tipo de apoio do poder público, às vezes tendo sua mercadoria apreendida e sendo classificados como “ambulantes” não formalizados, esse caso típico ocorre em São Paulo, Florianópolis, Porto Alegre, Campo Grande e outras (ibid).

Este quadro geral mostra que, além da falta de pesquisas, de dados estatísticos e do "limbo jurídico" a que estão expostos, o que se torna urgente para essa população é realmente articular os vários níveis do poder público em torno de um consenso sobre as políticas dirigidas a essa população e os atributos que cabem às diversas instâncias do estado. Além disso, ou em consonância com isso, valorizar a autonomia dessas comunidades no trabalho de suas associações como um instrumento legítimo de representação e de diálogo com o poder público, tal como definido pela Constituição brasileira e pela Convenção 169 da OIT ratificada pelo Brasil.

4 A FUNASA foi substituída em 2010 pela SESAI (Secretaria Especial de Saúde Indígena) do Ministério da Saúde. 


\section{2. $\mathrm{O}$ caso da cidade do Rio de Janeiro}

O Estado do Rio de Janeiro é o segundo estado mais rico da União e um dos piores em atendimento à população indígena. No Censo de 2000, a população indígena no Estado do Rio de Janeiro era de 35.934 pessoas e, na capital, de 15.622. Em 2010, assim como no resto do país, os valores tiveram uma diminuição significativa por conta do decréscimo do número de indígenas nas cidades, os números para o estado foram de 15.894 e, para a capital, 6.764. ${ }^{5}$ Mesmo assim, na relação entre cidades e Terras Indígenas o número é revelador, do total de 15.894 indígenas do estado, 450 estão em Terras Indígenas e 15.444 nas cidades. ${ }^{6}$ A diminuição da população indígena no estado foi de (-) 7,8 no total, sendo (-) 7,9 nas áreas urbanas e, (-) 6,8 na rural. O crescimento absoluto na capital entre 2000 e 2010 foi de (-) 8.858, e no conjunto dos outros municípios (-) 11.182. A taxa média de crescimento anual entre 2000 e 2010 foi de (-) 8,0\% na capital e (-) 7,7\% nas demais cidades. Segundo o IBGE (2012:14), "as perdas populacionais de indígenas foram significativas nas áreas urbanas de 20 Unidades da Federação, principalmente nos Estados de São Paulo, do Rio de Janeiro e de Minas Gerais. Nesses, o Censo Demográfico 2000 revelou os maiores incrementos populacionais em relação ao realizado em 1991”. A tabela abaixo apresenta os números.

\section{Tabela 2}

População autodeclarada indígena, participação relativa, crescimento absoluto e taxa média geométrica de crescimento anual nos municípios com maior número da população indígena, segundo a situação e domicílio Brasil - 2000/2010

\begin{tabular}{|c|c|c|c|c|c|c|c|c|c|}
\hline \multirow{3}{*}{$\begin{array}{l}\text { Unidades } \\
\text { da } \\
\text { Federação }\end{array}$} & \multirow{3}{*}{$\begin{array}{l}\text { Municípios mais populosos } \\
\text { e situação do domicílio }\end{array}$} & & & \multicolumn{4}{|c|}{ Participação relativa em relação } & \multirow{3}{*}{$\begin{array}{c}\begin{array}{c}\text { Crescimento } \\
\text { absoluto }\end{array} \\
2000 / 2010\end{array}$} & \multirow{3}{*}{$\begin{array}{c}\text { Taxa } \\
\text { média de } \\
\text { crescimentc } \\
\text { anual\% } \\
\text { 2000/2010 }\end{array}$} \\
\hline & & \multicolumn{2}{|c|}{ População residente } & \multicolumn{2}{|c|}{$\begin{array}{c}\text { Ao total do País } \\
\text { (\%) }\end{array}$} & \multicolumn{2}{|c|}{ Ao total do estado (\%) } & & \\
\hline & & 2000 & 2010 & 2000 & 2010 & 2000 & 2010 & & \\
\hline & Total & 81809 & 126593 & 11,1 & 15,5 & & & 44785 & 5,5 \\
\hline AM & São Gabriel da Cachoeira & 22853 & 2917 & 3,1 & 3,5 & 20,2 & 17,2 & 6164 & 2,4 \\
\hline AM & São Paulo de Olivença & 6634 & 14974 & 0,9 & 1,8 & 5,9 & 8,9 & 8340 & 8,5 \\
\hline AM & Tabatinga & 7255 & 14955 & 1,0 & 1,8 & 6,1 & 8,8 & 7600 & 7,4 \\
\hline SP & São Paulo & 18692 & 12977 & 2,5 & 1,6 & 29,3 & 31,0 & (-) 5715 & $(-) 3,6$ \\
\hline AM & Santa Isabel do Rio Negro & 3670 & 10794 & 0,5 & 1,3 & 3,2 & 6,4 & 7079 & 11,3 \\
\hline AM & Benjamin Constant & 3701 & 9833 & 0,5 & 1,2 & 3,3 & 5,8 & 6132 & 10,3 \\
\hline PE & Pesqueira & 2455 & 9335 & 0,3 & 1,1 & 7,1 & 17,5 & 6880 & 14,3 \\
\hline $\mathrm{RR}$ & Boa Vista & 6150 & 8550 & 0,8 & 1,0 & 21,9 & 17,2 & 2400 & 3,3 \\
\hline AM & Barcelos & 6187 & 8367 & 0,8 & 1,0 & 5,5 & 6,0 & 2180 & 3,1 \\
\hline \multirow[t]{2}{*}{ MG } & São João das Missões & 4211 & 7936 & 0,6 & 1,0 & 8,6 & 25,5 & 3725 & 6,5 \\
\hline & Urbana & 62592 & 66478 & 21,5 & 21,1 & & & (-) 10114 & $(-) 2,1$ \\
\hline SP & São Paulo & 17068 & 11918 & 4,5 & 3,8 & 29,0 & 31,4 & $(-) 5150$ & $(-) 3,5$ \\
\hline AM & São Gabriel da Cachoeira & 6029 & 11016 & 1,6 & 3,5 & 32,1 & 32,1 & 4987 & 6,2 \\
\hline BA & Salvador & 18712 & 7560 & 4,9 & 2,4 & 40,4 & 20,8 & (-) 11152 & $(-) 8,7$ \\
\hline RJ & Rio de Janeiro & 15622 & 6764 & 4,1 & 2,1 & 45,4 & 44,6 & (-) 8858 & $(-) 8,0$ \\
\hline
\end{tabular}

Fonte: IBGE (2012:16)

Esses números revelam pelo menos duas coisas, a diminuição da população indígena nas áreas rurais como parte do processo de migração para as cidades, assim como da urbanização dessas áreas, e, por outro lado, a diminuição dos números nas cidades por conta dos novos procedimentos censitários descritos no tópico anterior. ${ }^{7}$

5 No Rio de Janeiro os indígenas representam 0,1\% do total da população do estado, e 1,9\% do total da população indígena do país

6 http://www.ibge.gov.br/estadosat/temas.php?sigla=rj\&tema=censodemog2010_indig_univer

7 A presença de população indígena na cidade do Rio de Janeiro, no entanto, é bastante antiga. Como capital do Império e posteriormente da República, a cidade abrigou o SPI e diversos órgãos indigenistas (além de instituições de pesquisa sobre povos indígenas). Como mostra a pesquisa 
Como dito acima, em 2010 os indígenas no Estado do Rio de Janeiro eram 15.894, sendo que nas maiores cidades da Região Metropolitana do Rio de Janeiro (Grande Rio) os valores foram: Belford Roxo 316, Duque de Caxias 865, Guapimirim 26, Itaboraí 209, Itaguaí 149, Japeri 55, Magé 240, Maricá 140, Mesquita 150, Nilópolis 87, Niterói 655, Nova Iguaçu 747, Paracambi 29, Queimados 106, Rio de Janeiro 6.764, São Gonçalo 906, São João de Meriti 408, Seropédica 103, e, Tanguá 06.

Ou seja, nas maiores cidades da Grande Rio a população indígena soma 11.961 pessoas, ou $75,25 \%$ do total da população indígena do estado (a capital detém 44,6\% do total do estado). Portanto, a maior parte da população indígena urbana está concentrada na região da Grande Rio onde estão as maiores cidades do estado. ${ }^{8}$

\section{Figura 1}

Mapa com a densidade populacional indígena na Grande Rio

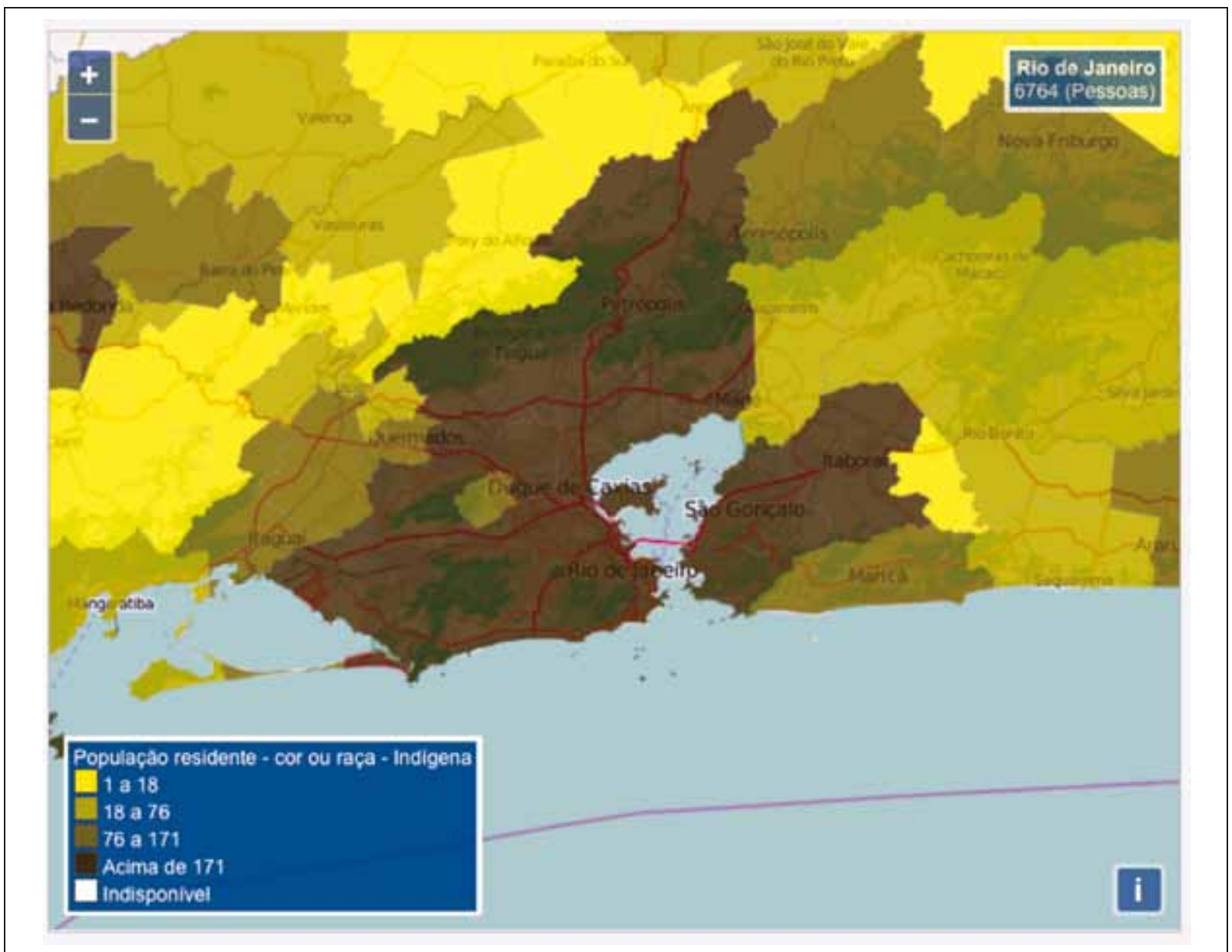

Fonte:http://cidades.ibge.gov.br/cartograma/mapa.php?lang =\&coduf =33\&codmun=330330\&idtema=67\&codv=v102\&search=rio-de-janeiro | niteroi $\mid$ censo-demografico-2010:-resultados-douniverso-caracteristicas-da-populacao-e-dos-domicilios-

A seguir, comparando-se a imagem gráfica da população indígena na Grande Rio, entre 1991 e 2010, é significativo o incremento dessa população na cidade do Rio de Janeiro:

de Silva (2014), sobre a presença indígena na capital fluminense durante o Império e começo da República, os indígenas chegavam à cidade por diversos motivos, desde busca de trabalho, principalmente no corpo militar, mas também em busca de reconhecimento de direitos, principalmente com relação à proteção do estado em conflitos fundiários na tentativa de conseguir apoio do órgão tutor (SPI) como também do corpo de funcionários, indigenistas e antropólogos, que trabalhavam nesse órgão e no Museu do Índio. Até a transferência da capital para Brasília a cidade do Rio de Janeiro era 0 espaço principal para onde indígenas do país inteiro vinham em busca de reconhecimento de direitos. As "viagens em busca de direitos" fazem parte do repertório da maioria das populações indígenas quando se trata da memória da luta social dessas comunidades em busca de direitos e acesso ao poder público.

8 Na Grande Rio as maiores etnias são: Fulni-ô, Potiguara, Pankararu, Guarani, Pataxó, Terena, Kaingang, Xavante e Pankararé. 
Figuras 2 e 3

Comparação da população indígena na Grande Rio, 1991 - 2010
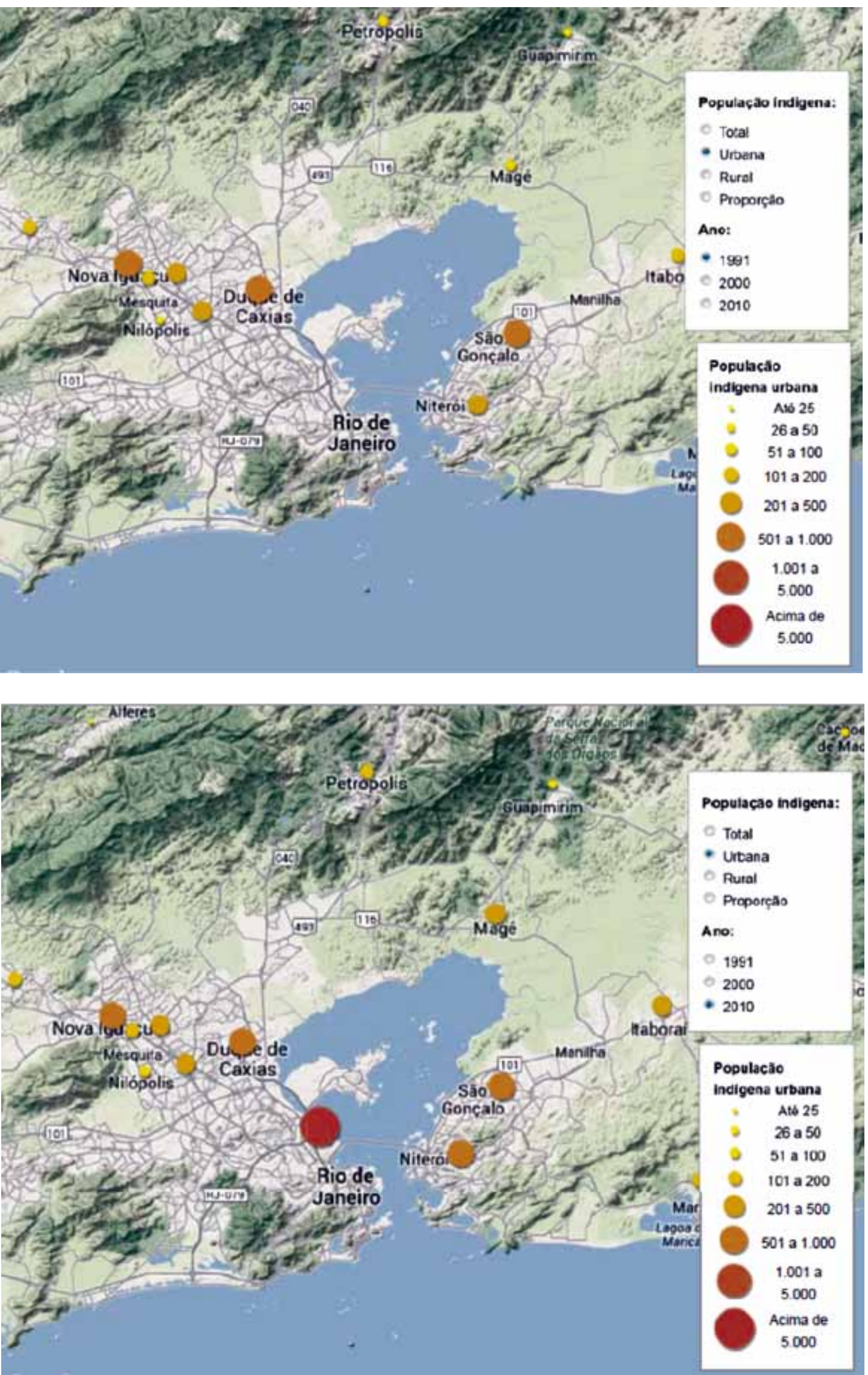

Fonte: http://indigenas.ibge.gov.br/mapas-indigenas-2 
Nesse sentido é muitíssimo relevante tentar entender como o poder público fluminense conseguiu se imiscuir da responsabilidade constitucional de apresentar e institucionalizar políticas públicas para os povos indígenas do estado, capital e cidades no entorno.

Um bom exemplo é o modo como a Casa do Índio do Rio de Janeiro (CASAI-RJ) está atualmente. A CASAI-RJ foi criada em 1968 para abrigar indígenas de todo o Brasil que necessitavam de tratamento de saúde especializado e que não era disponível nas suas regiões de origem. Localizada na Ilha do Governador, em um casarão de dois andares, hoje conta com 14 funcionários e abriga precariamente 18 indígenas de diversas etnias, incluindo idosos e crianças com deficiência física ou transtornos mentais.

A FUNAI foi a mantenedora da CASAI até 1999, quando a responsabilidade passou para a FUNASA, substituída, em 2010, pela Secretaria Especial de Saúde Indígena (Sesai) do Ministério da Saúde. Os indígenas são tratados pela rede pública de saúde no Município do Rio de Janeiro. No final de outubro de 2012 foi extinto o convênio do Ministério da Saúde com a Associação Rondon Brasil, responsável pela prestação de assistência à saúde aos indígenas no Sul, Sudeste e no Tocantins. Assim, desde esse momento a CASAI vem passando por inúmeras dificuldades financeiras.

Relatórios das Secretarias Estadual e Municipal de Saúde do Rio de Janeiro atestam que o local funciona como um centro asilar, sem tratamento continuado adequado às necessidades terapêuticas dos indígenas, embora conte com a solidariedade da sociedade e dos funcionários, que mantêm o local limpo, organizado e os doentes aparentemente bem tratados. Atualmente o local sobrevive de doações e, por conta do seu estado de precariedade, em dezembro de 2012, o Ministério Público Federal no Rio moveu uma ação civil pública contra a União e a FUNAI cobrando ampla reestruturação da unidade.

A fundadora e administradora da CASAI, Eunice Cariry, acompanha cada indígena pessoalmente. Sabe o ano em que cada um entrou na instituição e quantas vezes visitou sua aldeia de origem. Além disso, ela mantém uma memória documental e imagética, com vasto material fotográfico, da história de vida de cada um dos indígenas. A situação deste espaço (que existe em várias cidades brasileiras) serve de bom paradigma para averiguar a situação crítica das políticas públicas para essa parte de população no Estado do Rio de Janeiro, que está praticamente invisível nos processos de produção desse tipo de intervenção no estado e no município.

Nesse limbo jurídico e de políticas públicas, um pequeno grupo de indígenas (cerca de 12, entre eles Afonso Apurinã, Carlos Tukano, Garapirá Pataxó, Marize Guarani e Zé Guajajara) começou entre 2004 e 2005 a se reunir em espaços cedidos por sindicatos (como CUT, Sindipetro e outros). Esses pequenos encontros pretendiam organizar os indígenas na cidade a fim de estruturarem um movimento social em busca da regularização de políticas

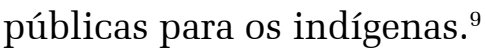

Em outubro de 2006 esse grupo organizou a ocupação do antigo Museu do Índio que estava abandonado desde 1977. Como o prédio se encontra na área externa do complexo do estádio do Maracanã, o grupo denominou a ocupação de Aldeia Maracanã. Os indígenas passaram assim a revitalizar o espaço, ao redor do prédio foram construídas pequenas habitações de taipa, hortas e árvores frutíferas foram plantadas e passou-se a realizar eventos

9 A partir deste ponto reproduzo, com algumas modificações, as notas que escrevi para a Comissão de Assuntos Indígenas (CAl) da Associação Brasileira de Antropologia (ABA), juntamente com o Professor Dr. João Pacheco de Oliveira, presidente dessa Comissão. [http://www.portal.abant.org. br/index.php/institucional/comissoes-e-comites?id=106]. 
de promoção das culturas indígenas, a venda de artesanato e encontros de indígenas que moram ou estão em trânsito na cidade. Nesse processo passaram a reivindicar do poder público o restauro do prédio e a destinação do mesmo à promoção das culturas e direitos indígenas.

No início da ocupação eram 17 etnias, com cerca de 47 indígenas, ao longo dessa ocupação esse número foi variando um pouco para mais e para menos, porém sempre com a manutenção das atividades e presença de moradores indígenas que se revezavam na organização do espaço. Além dos Guarani do Estado do Rio de Janeiro, as principais etnias presentes eram migrantes do Nordeste e Norte do país, eram elas: Apurinã (AM), Guajajara (MA), Kaiapó (PA), Karajá (GO), Krahô (MG), Krikati (MA), Pataxó (BA), Tabajara (CE), Tembé (MA), Tucano (AM) e Xukuru-Kariri (AL).

O pleito dos indígenas para o restauro do prédio pareceu legítimo pois todas as manifestações públicas feitas por técnicos e comissões que vistoriaram o local declararam que o edifício não corria o risco de desabamento e que podia ser plenamente restaurado. O prédio do antigo Museu do Índio tem evidente valor como patrimônio histórico e arquitetônico nacional. Construído na segunda metade do século XIX, foi destinado para uso do Duque de Saxe, genro de Dom Pedro II. Foi a primeira sede do SPI (1910) onde atuou o Marechal Candido Mariano Rondon, e do Museu do Índio fundado por Darcy Ribeiro em 1953. O prédio sediou a Seção de Estudos e Pesquisas do SPI da qual fazia parte o Museu, onde trabalharam importantes antropólogos brasileiros como Eduardo Galvão e Roberto Cardoso de Oliveira.

Em função dessa memória, seu resgate e importância para a história do indigenismo brasileiro e do movimento indígena, a Aldeia Maracanã veio ocupando o prédio e realizando a promoção da história e das formas de organização social e cultural indígenas. Além disso, a Aldeia Maracanã funcionava como polo agregador, instrumento de organização e campo de visibilidade da presença indígena na cidade. Essa ampla visibilidade lhes permitiu a ampliação do poder de voz de suas demandas, e acarretou numa crescente consciência de segmentos urbanos variados da vitalidade e da singularidade da presença indígena no Brasil contemporâneo.

Embora o grupo tivesse insistido bastante na promoção de um diálogo com o poder público exigindo a participação do estado na reforma e promoção do espaço para a causa indígena, o governo do Estado do Rio de Janeiro esteve em silêncio sobre o caso até fins de 2012, quando passou a assediar o grupo através de investidas jurídicas para a desocupação do espaço e, desde o dia 12/01/2013, também com a intimidação através da demonstração de força de seu aparato policial (batalhão de Choque da PM), isso mesmo sem uma ordem judicial (liminar de imissão de posse). Assim, a situação dos indígenas se tornou problemática com a pressão e inúmeras tentativas realizadas pelo governo na tentativa de dissuadi-los de continuar no local. Abaixo apresento uma síntese dos eventos mais significativos que demonstram o esforço de luta e também dos instrumentos que acarretaram a expulsão do grupo do local. ${ }^{10}$

No dia 15/01/2013 os indígenas da Aldeia Maracanã estiveram em reunião na Secretaria de Estado de Assistência Social e Direitos Humanos (SEASDH-RJ). Eles haviam sido chamados

$10 \mathrm{~A}$ expulsão dos indígenas do local estava inserida na política das reformas que o governo estava realizando por conta da realização da Copa do Mundo de 2014. Todo o complexo do Maracanã passou por um processo de remoções forçadas de comunidades pobres, reforma e transformação dos equipamentos públicos ali instalados. 
para negociar uma alternativa em relação à demolição do antigo prédio do Museu do Índio e a realocação dos indígenas. Apesar de um início de diálogo, não se chegou a um consenso, pois a SEASDH frisou que a negociação não seria obstáculo para a derrubada do prédio e que o governo não tinha em mente um novo local para eles. A secretaria ofereceu o pagamento de aluguel social $(\mathrm{R} \$ 400,00)$ e ficou de apresentar uma proposta por escrito de um novo local em que os indígenas poderiam ficar.

No dia 16/01/2013 o governador do estado (RJ) e a SEASDH encaminharam carta proposta aos indígenas se comprometendo com uma série de medidas visando minimizar o impacto negativo das ações programadas. Dentre estas estava a criação de um Centro de Referência da Cultura dos Povos Indígenas, em local a ser definido, mas próximo ao complexo esportivo do Maracanã. Também foi apresentada a criação, pela SEASDH, de um Conselho Estadual de Direitos Indígenas, que estaria incumbido de monitorar o Centro de Referência da Cultura dos Povos Indígenas, além de atuar como órgão consultivo do governo do estado na formulação de políticas públicas para os indígenas. O documento afirmava que, ao serem aceitos tais termos, os indígenas em contrapartida deveriam desocupar o imóvel em litígio e a SEASDH prestaria assistência para viabilizar o transporte para o retorno às aldeias de origem ou abrigo em equipamentos estatais no Rio de Janeiro.

No dia 17/01/2013 os indígenas receberam uma notificação da Procuradoria do Patrimônio e Meio Ambiente, da Procuradoria Geral do Estado do Rio de Janeiro, informando que o imóvel em litígio havia sido adquirido pelo estado, no dia 29/10/2012, pelo valor de $\mathrm{R} \$ 60$ milhões de reais. O documento requeria com urgência que os indígenas desocupassem o imóvel no prazo máximo de 10 dias.

Ainda no dia 17/01/2013 o Conselho Estadual de Defesa dos Direitos Humanos do Rio de Janeiro (CEDDH/RJ) emitiu nota pública onde manifestou "seu profundo repúdio à tentativa de demolição do prédio que abrigou o primeiro Museu do Índio da América Latina, atual Aldeia Maracanã”. A nota lembrava que o Conselho Municipal de Proteção do Patrimônio Cultural do Rio de Janeiro (CPMC/RJ), "por determinação do Decreto Municipal 20.048/2001, tem competência para deliberar acerca da demolição e da alteração das edificações construídas até 1937. Em dezembro de 2012, o CPMC/RJ posicionou-se contrário à demolição do antigo Museu do Índio". Assim, o governo do estado estava "em consonante desacordo com a legislação municipal [ao] reafirmar a necessidade de demolição do prédio”.

Segundo o Jornal do Brasil (25/01/2013), em nota datada de 17/01/2013, a então presidente da Funai, Marta Azevedo, também havia se pronunciado sobre a questão. Na nota ela esclarecia que "as prioridades do órgão são as ações em terras indígenas e nenhum encaminhamento poderia ser dado sobre o pedido, uma vez que tal reivindicação foge às atribuições e competências do órgão indigenista”. Segundo tal notícia a Funai teria alertado "que, enquanto órgão indigenista oficial do governo federal, a FUNAI não tem como finalidade atender demandas dos indígenas individualmente, e que não há políticas específicas e diferenciadas para atendimento de índios na cidade".

No dia 21/01/2013 os indígenas estiveram em reunião no Instituto do Patrimônio Histórico e Artístico Nacional (IPHAN) no Rio de Janeiro onde foram informados que o órgão levaria o assunto da proteção do antigo Museu do Índio à presidente do Instituto, Jurema Machado. No dia 24/01/2013, segundo o Jornal do Brasil (de 26/01/2013), a então ministra da Cultura, Marta Suplicy, defendeu a preservação do imóvel e pediu ao governo estadual uma maior "sensibilidade" no trato com a questão. 
No dia 26/01/2013 foi deferida uma liminar de manutenção de posse do prédio em favor de uma das lideranças da Aldeia (Afonso Apurinã) pelo juiz Andre Felipe Alves da Costa Tredinnick da Vara do Plantão Judicial do Tribunal de Justiça do Estado do Rio de Janeiro. O juiz entendeu que a notificação para a desocupação do imóvel pelos indígenas até o dia 27/01/2013 não era legal face aos direitos indígenas fundamentais determinados pela constituição federal e outras normas jurídicas internacionais.

No dia 28/01/2013 o governo do Estado do Rio de Janeiro, através de sua assessoria de imprensa, emitiu nota onde afirmava sua decisão de "preservar e tombar" o prédio do antigo Museu do Índio. A nota dizia que "o Estado ouviu as considerações da sociedade a respeito do prédio histórico, datado de 1862, analisou estudos de dispersão do estádio e concluiu que é possível manter o prédio no local”. Mais adiante a nota afirmava que o governo estava tomando providências para que o local fosse "desocupado dos seus invasores".

No dia 29/01/2013 a Defensoria Pública da União no Rio de Janeiro (DPU/RJ) divulgou nota sobre o recuo do governo na decisão de demolir o prédio. A nota dizia entre outras coisas que a DPU/RJ havia tomado conhecimento da decisão do governo pela imprensa e que ela não havia recebido nenhum comunicado oficial e lamentava tal atitude que "optou por divulgar sua 'nova' posição à imprensa, sem fazer o mesmo em relação à parte interessada, os índios da Aldeia Maracanã". Destacava ainda que "não havendo notificação oficial, não há informação oficial. Ou seja, uma 'nota à imprensa' não gera nenhum compromisso legal”.

No dia 20/02/2013 o governador do Estado do Rio de Janeiro, Sérgio Cabral, afirmou em entrevista, que no antigo Museu do Índio seria criado o Museu do Comitê Olímpico Brasileiro (COB). Os indígenas afirmaram na ocasião que não haviam recebido qualquer informação oficial do governo sobre essa decisão. A DPU/RJ também informou que não fora comunicada oficialmente sobre a nova posição do governo estadual.

No dia 25/02/2013 foi publicado no Diário Oficial do Estado do Rio de Janeiro, o edital de concessão do Estádio do Maracanã. Esse edital afirma que o Museu do Índio seria preservado, mas que os indígenas deveriam ser retirados e o prédio abrigaria no futuro o Memorial Olímpico, que ficaria sob a gestão do Comitê Olímpico Brasileiro (COB). Em reunião dos indígenas com a SEASDH, no dia 07/03/2013, foi proposto que o antigo Museu do Índio não abrigasse somente o Museu Olímpico mas que o espaço fosse dividido entre o COB e os indígenas.

No dia 11/03/2013 o Juiz Federal da $8^{\text {a }}$ Vara Federal, Renato Cesar Pessanha de Souza, despachou um mandato de imissão de posse em favor do Estado do Rio de Janeiro e contra o Cacique da Aldeia Maracanã, Carlos Tukano, "e outros". A $8^{\text {a }}$ Vara da Justiça Federal do Rio de Janeiro esclareceu que o prazo para a desocupação do antigo prédio do Museu do Índio era de três dias a contar do dia 18/03/2013.

No dia 12/03/2013 em nova reunião dos indígenas com a SEASDH não foi possível chegar a um consenso sobre a divisão do prédio do antigo Museu do Índio entre eles e a COB. Em nota sobre o encontro realizado no dia 07/03/2013 a SEASDH informou que não havia apresentado anteriormente proposta sobre a divisão do prédio entre os indígenas e o COB. Segundo a nota, o órgão apenas informou sobre a realocação dos indígenas para locais alternativos.

No dia 14/03/2013 foi votado na Câmara dos Vereadores do Rio de Janeiro o Projeto de Lei 1536/2012 sobre o tombamento da Aldeia Maracanã como Centro Cultural Indígena no local onde ela já se encontrava. Por 17 votos contra e 13 a favor, o projeto de lei no 1536/2012 foi derrotado. 
No dia 15/03/2013 o defensor público federal Daniel Macedo, titular do $2^{\circ}$ Ofício de Direitos Humanos e Tutela Coletiva da DPU/RJ, entrou com agravo de instrumento no Tribunal Regional Federal do Rio contra a decisão da $8^{\mathrm{a}}$ Vara Federal Cível do Rio que concedeu imissão de posse em favor do governo estadual. Ele compareceu a Aldeia Maracanã com o objetivo de notificá-los da decisão.

Na tarde do dia 15/03/2013, a SEASDH lançou nota dizendo que "mais uma vez" havia "tentado o diálogo", pois

apresentou uma proposta por escrito e assinada pelo governador, garantiu a construção de um Centro de Referência na Quinta da Boa Vista e a criação do Conselho Estadual dos Direitos das Populações Indígenas e ofereceu ainda transporte, hospedagem e alimentação ou aluguel social até a conclusão do Centro de Referência. Infelizmente, o governo nunca obteve uma resposta formal. A secretaria, conforme consta no mandado de imissão de posse, reafirma as suas propostas e aguarda um posicionamento por parte dos índios.

A SEASDH ofereceu alocar provisoriamente os indígenas em 30 quartos de um hotel no centro. Segundo o Jornal do Brasil (18/03/2013), o defensor público da União Daniel Macedo vistoriou o hotel e considerou o local "indigno".

No dia 18/03/2013 o defensor público Daniel Macedo ingressou novamente no Tribunal Regional Federal da $2^{\text {a }}$ Região (TRF2) com um recurso de agravo de instrumento na tentativa de reverter a situação. Nesse instrumento ele pedia prazo de 15 dias para que o governo apresentasse aos indígenas suas propostas detalhadas.

No dia 19/03/2013, Adalberto Wilson Spier, Diretor da Secretaria da $8^{\text {a }}$ Vara Federal, tornou os autos conclusos. Assim, ele colocou os indígenas em uma situação de urgência quanto à presença iminente do Batalhão de Choque da PM para proceder à desocupação do imóvel. De acordo com a Justiça Federal do Rio, a ordem judicial podia ser cumprida a partir das 6 h de quinta-feira (21/03/2013), quando já teria expirado o prazo de 72 horas.

$\mathrm{Na}$ ocasião, o defensor público Daniel Macedo afirmou em diversos meios de comunicação que temia um confronto entre os indígenas e o Batalhão de Choque. Esse defensor também afirmou que o impasse decorria da falta de definição da proposta do governo estadual, que, ao não fixar prazo nem local para a construção do Centro de Referência da Cultura Indígena, colocava os indígenas em um estado de confusão e precariedade quanto ao seu futuro pessoal, coletivo e dos seus projetos em andamento.

Como concluímos na nota da CAI/ABA, o que a cronologia dos fatos ocorridos deixou evidente foi o seguinte: a) em função da decidida resistência dos indígenas, de manifestações de apoio a estes por parte da sociedade civil e de algumas autoridades públicas (o CPMC/RJ, a CEDDH/RJ, o IPHAN, o DPU/RJ), o governo do estado anunciou haver mudado sua decisão quanto à derrubada do prédio e buscou através da SEASDH estabelecer um diálogo com os indígenas, acenando com medidas mitigatórias e compensatórias; b) Atuando de forma confusa e por meio de ações desencontradas, resultado de manifestações independentes de diferentes setores (a Procuradoria do Patrimônio e Meio Ambiente, a assessoria de imprensa do governador, ações judiciais, além da SEASDH), o governo estadual não chegou a criar uma interlocução efetiva visando à solução do problema, nem conseguiu estabelecer, por meio da formalização de uma proposta e da especificação dos prazos e meios nela contidos, a necessária confiança e credibilidade para a condução das negociações.

Desse modo, no dia 22/03/2013, os indígenas foram expulsos sob forte aparato policial com o uso exagerado da força do Batalhão de Choque da PM. O evento teve ampla repercussão midiática e colocou o caso entre as principais notícias da semana, exibindo imagens que 
deixaram a audiência nacional e internacional chocadas. A maior parte do grupo foi alojada em containers improvisados em um espaço público conhecido como Colônia Curupaiti ${ }^{11}$ na qual permanecem até hoje, mais de um ano após os fatos. ${ }^{12}$

Contudo um evento não previsto mudou os rumos da história, os protestos no Brasil em 2013, também conhecidos como Jornadas de Junho ${ }^{13}$. Nesse mês o país foi surpreendido com uma série de manifestações populares por todo o país que inicialmente surgiram para contestar os aumentos nas tarifas de transporte público e depois ganharam amplo apoio popular ampliando o repertório de demandas. Essas manifestações foram as maiores mobilizações no país desde as manifestações pelo impeachment do então presidente Fernando Collor de Mello em 1992. A cidade do Rio de Janeiro foi o epicentro de inúmeras manifestações, incluindo a maior do país, no dia 20/06/2013 em que cerca de 300 mil pessoas se concentraram no centro da cidade. Nessas manifestações os indígenas da Aldeia Maracanã e seus aliados conseguiram ampliar a visibilidade da questão da Aldeia colocando o evento da expulsão dos indígenas como carro-chefe na frente das marchas.

Após esse período conturbado, o governador do Rio de Janeiro, Sérgio Cabral (PMDB), na tentativa de minimizar o prejuízo da imagem do governo e tentar a continuidade do seu partido na sucessão governamental que aconteceria em outubro (2014), revogou inúmeras medidas impopulares, dentre elas o destino da Aldeia Maracanã.

Desse modo, no dia 29/07/2013 o governador do Rio de Janeiro anunciou a devolução do Antigo Museu do Índio aos indígenas e no dia seguinte promoveu uma reunião entre a secretária estadual de Cultura, Adriana Rattes, e indígenas da Aldeia Maracanã. Em nota ${ }^{14}$ dessa Secretaria do dia 31/07/2013 o governo do estado se comprometia a promover um calendário de reuniões para definir a elaboração do projeto (nome, estrutura, cronograma e modelo de gestão) do futuro Centro de Referência da Cultura Indígena. A secretária, Adriana Rattes, propôs na ocasião que o Centro fosse uma instituição pública estadual e sua gestão composta por um conselho permanente formado por representantes do estado, indígenas (Aldeia Maracanã e de outras etnias do estado e do país) e sociedade civil. Na nota divulgada a secretária afirmou que

\footnotetext{
Os objetivos principais do centro serão os de promover, preservar e difundir a história, os valores, os conhecimentos e todos os aspectos culturais dos indígenas brasileiros, com foco especial nos grupos que vivem ou viveram nas diversas regiões do Estado do Rio de Janeiro. O centro será ainda um ponto de formação, referência e apoio para os índios contemporâneos, diante dos desafios e das transformações culturais por que passam as diversas etnias em suas vivências nas aldeias e também no espaço urbano.
}

No dia 16/12/2013 o governo do Estado do Rio de Janeiro publicou o decreto $\mathrm{n}^{\mathrm{o}} 44.525$ que promoveu a afetação do prédio do antigo Museu do Índio a atividades culturais indígenas. O decreto dizia em resumo:

11 A Colônia (ou Hospital) Curupaiti é uma antiga colônia de portadores de hanseníase situada em Jacarepaguá (Rio de Janeiro). Foi criado em 1929 para abrigar pessoas atingidas pela hanseníase. Hoje atende cerca de duas mil pessoas. Na Colônia não há risco de contágio pela hanseníase hoje erradicada. Fonte: http://pt.wikipedia.org/wiki/Hospital_Curupaiti [com modificações].

12 A informação se refere ao período de março/abril de 2014. Depois de muita negociação, que implicou a articulação de uma série de apoiadores, esse grupo conseguiu se transferir para um edifício com 20 apartamentos, de uso exclusivo dos indígenas. 0 edifício no qual estão morando atualmente situa-se na rua Frei Caneca, no centro da cidade do Rio de Janeiro. Ele faz parte de um conjunto habitacional construído pelo Governo Federal, através do programa social denominado de "Minha Casa, Minha Vida" (ver adiante). Sobre a condição atual desses indígenas há poucas informações disponíveis, ver, por exemplo, o site OPIERJ (http://opierj.com.br) desenvolvido pelo Proíndio (UERJ).

13 Fonte: http://pt.wikipedia.org/wiki/Manifesta\%C3\%A7\%C3\%B5es_no_Brasil_em_2013 [com modificações].

14 http://www.cultura.rj.gov.br/imprime-colaboracao/discutida-a-criacao-de-centro-estadual-de-estudos-e-difusao-da-cultura-indigena 
CONSIDERANDO: - o interesse de implantar um Centro de Referência da Cultura dos Povos Indígenas/ Universidade Indígena, que preserve e promova os usos, costumes e tradições culturais das etnias indígenas (...); - que o governo do Estado do Rio de Janeiro reconhece a importância da cultura e história dos povos originários brasileiros; - a necessidade de políticas que atendam a realidade dos povos indígenas que vivem nos centros urbanos e que necessitam preservar sua identidade étnica; e - a necessidade da promoção do intercâmbio cultural das práticas dos povos indígenas com a população urbana.

DECRETA: Art. $1^{\circ}$ - O prédio da Avenida Maracanã (...), conhecido como antigo Museu do Índio, constitui bem público ora afetado à instalação de um Centro de Referência da Cultura dos Povos Indígenas/Universidade Indígena, para o desenvolvimento de atividades culturais relacionadas aos usos, costumes e tradições indígenas.

Art. $2^{\circ}$ - Para a execução do referido Centro de Referência da Cultura dos Povos Indígenas/Universidade Indígena compete à Secretaria de Estado de Cultura:

a) definir, ouvidas as lideranças indígenas do Estado e instituições que formalmente destinem-se à defesa dos direitos e interesses dos povos indígenas, o programa de uso cultural do bem afetado, para que seja estabelecido no local o Centro de Referência da Cultura dos Povos Indígenas/Universidade Indígena;

b) envidar esforços para a captação dos recursos privados e/ou públicos necessários ao patrocínio e financiamento da implantação do Centro de Referência da Cultura dos Povos Indígenas/Universidade Indígena;

c) envidar esforços para estabelecer convênios, parcerias, e demais instrumentos jurídicos permitidos em lei, com os órgãos responsáveis pela assistência aos povos indígenas e de apoio à questão indígena.

Art. $3^{\circ}$ - A Secretaria de Estado de Cultura adotará as providências necessárias ao cumprimento deste Decreto.

No dia 19/12/2013, foi assinado o protocolo de intenções celebrado entre o Estado do Rio de Janeiro, através da Secretaria de Estado da Cultura (SEC/RJ) com os "povos indígenas do Brasil” e organizações indígenas, visando à implantação do Centro de Referência da Cultura dos Povos Indígenas/Universidade Indígena com intervenção da fundação Darcy Ribeiro.

Dentre inúmeras cláusulas do termo destaco as seguintes:

$01^{\mathrm{a}}$ - O Centro de Referência, de pleno acesso da população, terá como missão o desenvolvimento de atividades artísticas, cursos de formação e qualificação, pesquisas, exposições, eventos e seminários, entre outras atividades culturais e manterá permanente diálogo sobre a questão indígena nacional, a fim de promover o desenvolvimento sociocultural das comunidades indígenas brasileiras.

E, sobre a competência da Secretaria de Estado da Cultura (SEC/RJ), ficou firmado que ela deverá:

a) Garantir, mediante Orçamento próprio por meio de recursos financeiros de terceiros, a implantação do Centro de Referência;

b) Envidar esforços para atrair parceiros institucionais e financeiros para o projeto;

c) Fornecer os recursos humanos, técnicos e logísticos para desenvolvimento do projeto do Centro de Referência;

d) Criar uma Comissão onde tenham assento representantes desta Secretaria, dos diversos povos indígenas, instituições que formalmente se destinem a defesa dos direitos e interesses dos povos indígenas e membros da sociedade civil, garantindo a paridade entre indígenas e não indígenas nesta Comissão com vistas a elaborar o conteúdo programático e a forma de gestão pública do futuro Centro de Referência;

i) Promover o intercâmbio entre os povos indígenas, propor parcerias e acordos com os Governos Federal, Estadual e Municipais, além de outras instituições, com o objetivo de difundir, valorizar, revitalizar, resgatar a memória e preservar a cultura indígena.

O termo contou então com a assinatura de 41 indígenas de todo o país presentes ao evento. Após isso a SEC/RJ ${ }^{15}$ montou três grupos de trabalho (GTs) para encaminharem propostas sobre a organização do Centro de Referência. Os três grupos eram: a) regularização do espaço do Centro de Referência (atribuição do decreto $\mathrm{n}^{\circ} 44.525$, definição de licitação e obras de

15 Até então, a SEC/RJ realiza quase nenhum tipo de política pública para os indígenas, essa "atenção" estava circunscrita a ajuda de custo e solicitação de espaço para a venda de artesanato indígena em feiras da cidade (p.ex.: Lavradio e Providência), alguma participação dos indígenas como "oficineiros" no projeto das Bibliotecas-Parque e alguma ajuda de custo na produção de pequenos projetos culturais independentes. 
restauro do prédio); b) Conteúdo Cultural (a cargo de um grupo de indígenas, mediadores da Fundação Darcy Ribeiro e Pró-Índio/UERJ); e c) uso provisório do espaço do antigo Museu do Índio. Além disso a SEC/RJ mediou junto à Secretaria Estadual de Direitos Humanos a constituição de um Conselho Estadual dos Direitos dos Povos Indígenas e a transferência dos indígenas dos alojamentos da Colônia Curupaiti para um conjunto de 20 apartamentos em um bloco de um conjunto habitacional do projeto do governo federal conhecido como "Minha Casa, Minha Vida" na rua Frei Caneca, centro da cidade do Rio de Janeiro (sendo o repasse dos imóveis sem ônus para os indígenas). ${ }^{16}$

Na proposta preliminar do GT de conteúdo ${ }^{17}$ foram definidos, entre outras atividades, as seguintes:

\footnotetext{
a) Missão: Criar e manter um Centro de Referência da Cultura Viva dos Povos Indígenas no Rio de Janeiro que valorize e divulgue a história, cultura e contribuição dos Povos Originários na formação do Brasil com a missão de desconstruir estereótipos e preconceitos com relação aos indígenas, bem como realizar cursos de formação de novas lideranças indígenas, qualificando e aprimorando seus conhecimentos, com objetivo de garantir os direitos indígenas e promover o desenvolvimento sociocultural e econômico das comunidades indígenas brasileiras. Deverá ser ainda uma tribuna livre e permanente para a discussão da questão indígena nacional;

b) Visão: Ser concebido e implantado com gestão protagonista dos próprios índios, de forma que possa evoluir para uma Universidade Indígena a ser estruturada com base na cultura tradicional dos Povos Originários;

c) Objetivos: difusão cultural, formação, capacitação, intercâmbio e acolhimento;

d) Oportunidades de utilização dos espaços do prédio: apresentações culturais, exposições permanentes e temporárias, auditório e salas multimídia para cursos e oficinas, biblioteca, loja de artesanato, núcleo de produção audiovisual, restaurante e sede do Cona) selho Estadual dos Direitos Indígenas.
}

Assim, em 14/03/14, esse GT apresentou a proposta de programação para o lançamento do Centro de Referência para o "Dia do Índio" de 19 de abril de 2014 com uma programação cultural da semana de lançamento, de 19 a 30 de abril de 2014. Dentre os objetivos estratégicos estão o de "Fundamentar a decisão do Governo do Estado de destinar o prédio para a instalação de um Centro Cultural Indígena" e "Divulgar um calendário de atividades culturais indígenas que serão desenvolvidas no período de maio a dezembro de 2014”. Dentre os parceiros do projeto estão a SEC/RJ, a recém-fundada Associação Indígena Aldeia Maracanã (AIAM), o Instituto Estadual de Patrimônio Artístico e Cultural (INEPAC) - responsável pelo projeto de restauro do prédio, a Comissão Pró-Índio (UERJ), o Museu do Índio do Rio de Janeiro (FUNAI), a Fundação Darcy Ribeiro (FUNDAR) e o projeto Vídeo Nas Aldeias (VNA). Dentre as iniciativas que devem marcar o lançamento do Centro de Referência, estão a entrega das chaves dos apartamentos do Minha Casa Indígena, a posse do Conselho Estadual dos Direitos dos Povos Indígenas do Rio de Janeiro e o lançamento do edital do projeto arquitetônico do Centro de Referência.

\section{Conclusão}

O conflito agrário e a intervenção do poder tutelar constituíram áreas restritas para o trânsito do indígena. O meio de sobrevivência para muitos indígenas foi o trabalho assalariado nas fazendas e como mão de obra na construção civil nas cidades vizinhas e capitais do país. A diáspora indígena para as cidades e capitais econômicas do país constituiu a consequente

16 Local onde a maioria desses indígenas permanece até atualmente.

17 Esse GT era formado pelos indígenas: Marize Guarani, Cristino Wapichana, Carlos Tukano, Afonso Apurinã; e pelos apoiadores mediadores da Fundação Darcy Ribeiro: Cordelia Fourneau e Toni Lotar. A proposta foi elaborada em reunião do GT na Fundação Darcy Ribeiro no dia 27/08/2013 e entregue formalmente à SEC/RJ no dia 28/08/13. 
invisibilidade dessa população no meio urbano. Nesse ambiente, encontraram-se com a atualização do projeto do poder tutelar na ampliação de categorias surgidas historicamente no seu contexto (p.ex.: “desaldeados”, “assimilados”, “aculturados” e outras).

Como mostra o exemplo paradigmático do Rio de Janeiro, os indígenas nas cidades têm muita dificuldade em terem seus direitos efetivados, o principal instrumento de contestação da "autenticidade" dos indígenas, seja do poder público, que os mantém administrativamente num "limbo jurídico", seja a própria sociedade nacional que os estereotipa, é a suposição de que o fato desses indígenas estarem nas cidades não os qualificaria como indígenas e, portanto, não deveriam ter acesso a direitos específicos, como saúde e educação.

O discurso anti-indígena nas cidades atualiza o projeto do poder tutelar, e suas categorias, como a de "desaldeados", que carrega em seu sentido a suposição de que os indígenas abdicaram da "proteção" e assistência dos órgãos públicos (FUNAI e outros). Essa é uma forma de preconceito político-administrativo. O preconceito político-administrativo mantém a política do SPI ao tempo em que diminui as atribuições da FUNAI, constituindo uma omissão legítima, sua conclusão política é equacionar a diáspora com o etnocídio.

Como escreveu Souza Lima (1995) acerca da atuação do poder tutelar, a "guerra de conquista" é também uma empresa cognitiva, orientada por procedimentos semióticos. Esse elemento talvez seja o principal mecanismo político de atualização da "política como guerra" atualmente vivenciado pelos povos indígenas. Esse mecanismo do "jogo do poder" pode ser definido como um tipo de preconceito, já que é o preconceito um dos instrumentos por excelência de constituição da invisibilidade social do indígena e, portanto, coloca em risco os direitos garantidos a essa parcela da população pela própria Constituição.

Interpreto essa noção de preconceito como uma violência simbólica, tal como a definiu Bourdieu (1989:15), ou seja, como uma, "forma transformada, quer dizer, irreconhecível, transfigurada e legitimada, das outras formas de poder", onde "o trabalho de dissimulação e de transfiguração (numa palavra, de eufemização) que garante uma verdadeira transubstanciação das relações de força fazendo ignorar-reconhecer a violência que elas encerram objetivamente e transformando-as assim em poder simbólico, capaz de produzir efeitos reais sem dispêndio de energia."

O "preconceito" é experimentado como a continuidade da guerra de conquista dos povos indígenas via a política. Esse tipo de preconceito pode ser caracterizado como um preconceito de autenticidade, cujo efeito, propriamente ideológico, "consiste precisamente na imposição de sistemas de classificação políticos sob a aparência legítima de taxonomias filosóficas, religiosas, jurídicas etc.” (ibid.:14).

Essa violência simbólica tende assim a ser combatida pelos indígenas refutando seus termos-chave (p.ex.: "aculturados", "desaldeados”). Os indígenas assim parecem ter compreendido como "luta social" o processo definido por Bourdieu (ibid.:15) como a tomada de consciência do arbitrário:

a destruição deste poder de imposição simbólico radicado no desconhecimento supõe a tomada de consciência do arbitrário, quer dizer, a revelação da verdade objetiva e o aniquilamento da crença: é na medida em que o discurso heterodoxo destrói as falsas evidências da ortodoxia, restauração fictícia da doxa, e lhe neutraliza o poder de desmobilização, que ele encerra um poder simbólico de mobilização e de subversão, poder de tornar atual o poder potencial das classes dominadas.

Seguindo a ideia defendida por Oliveira (1999b:08) de que "uma compreensão das sociedades e culturas indígenas não pode passar sem uma reflexão e recuperação críticas de 
sua dimensão histórica”, apresentei neste artigo um capítulo da agência indígena na cidade do Rio de Janeiro enfatizando o seu "surgimento" na atualidade com a contestação do "limbo jurídico” ao qual estavam submetidos.

\section{Referências bibliográficas}

ABDALA, Victor. Cresce número de indígenas que vive em cidades brasileiras, 2010. Disponível em: http://www.brasil.gov.br/noticias/arquivos/2010/03/24/numero-de-indigenasvivendo-em-cidades-e-cada-vez-maior-no-brasil (acessado em: 19/01/2011).

BAINES, Stephen G. As chamadas “aldeias urbanas” ou índios na cidade. 2004. Disponível em: http://www.ipol.org.br/imprimir.php?cod=212 (acesso em: 19/01/2011).

BOURDIEU, Pierre. O Poder Simbólico. Lisboa: Difel, 1989.

BRASIL DE FATO. Editorial. Publicado no dia 08/10/2009.

CARVALHO, Priscila D. de. Índios na Cidade, 2007. Disponível em: http://www. webbrasilindigena.org/?page_id=177 (acesso em: 19/01/2011).

IBGE, Instituto Brasileiro de Geografia e Estatística. Os indígenas no Censo Demográfico 2010: Primeiras considerações com base no quesito cor ou raça. Rio de Janeiro: IBGE, 2012. 31p.

OLIVEIRA, João Pacheco de. Uma Etnologia dos ‘Índios Misturados’? Situação Colonial, Territorialização e Fluxos Culturais. In: OLIVEIRA, J. P. de. A Viagem de Volta. Etnicidade, Política e Reelaboração Cultural no Nordeste Indígena. Rio de Janeiro: Contra Capa, 1999a.

. Ensaios em antropologia histórica. Rio de janeiro: Editora UFRJ, 1999b.

SILVA, Ana Paula da. Os arquivos como territórios indígenas da cidade do Rio de Janeiro no século XIX. Qualificação de doutorado apresentada ao Programa de Pós-Graduação em Memória Social, da Universidade Federal do Estado do Rio de Janeiro-RJ, 2014.

SOUZA LIMA, Antonio Carlos de. Um Grande Cerco de Paz. Poder Tutelar, Indianidade e Formação do Estado no Brasil. Petrópolis: Vozes, 1995. 335 pp.

copyright (C) creative Albuquerque 
